\title{
Synthesis and Characterization of Dimethacrylate Monomer with High Molecular Weight for Root Canal Filling Materials
}

\author{
Fang Liu ${ }^{1, *}$, Jing-wei He ${ }^{1}$, Zheng-mei Lin ${ }^{2}$, Jun-qi Ling ${ }^{2}$ and De-min Jia ${ }^{1}$ \\ ${ }^{1}$ College of Materials Science and Engineering, South China University of Technology, Guangzhou \\ 510641, China; E-mails: lxhjw002@126.com. E-mail: psdmjia@scut.edu.cn \\ ${ }^{2}$ Guanghua College of Stomatology, Institute of Stomatology, Sun Yat-sen University, Guangzhou \\ 510060, China; E-mails: linzhengmei@yahoo.com.cn. E-mail: ghjqling@126.com
}

* Author to whom correspondence should be addressed. E-mail: mcfliu@126.com

Received: 18 November 2006; in revised form: 4 December 2006 / Accepted: 4 December 2006 / Published: 7 December 2006

\begin{abstract}
A new dimethacrylate monomer 9,9'-bis[4-(2'-hydroxy-3'-methacryloyloxypropoxy)phenyl] fluorene (3) with a molecular weight of 634 was synthesized in $51.4 \%$ yield by addition of a glycidyl ether group to 9,9'-bis(4-hydroxyphenyl) fluorene (1) by the reaction of compound $\mathbf{1}$ with epichlorohydrin, and then introducing the methacrylate moiety by the reaction of the epoxy group with methacrylic acid. The structure of monomer 3 was confirmed by FT-IR, ${ }^{1} \mathrm{H}-\mathrm{NMR}$, mass spectra and elemental analysis.
\end{abstract}

Keywords: Dimethacrylates, high molecular weight, synthesis, characterization.

\section{Introduction}

Polymethyl methacrylate was firstly used in tooth restoration by German scientists in 1937. After that polymethacrylates were used extensively as dental materials, e.g. as dental restorative materials and primary resins of root canal sealers in root canal treatment, due to their good biocompatibility and adhesive properties [1]. The main drawback of methacrylate monomers is volumetric shrinkage during their polymerization, so marginal gaps between tooth and sealer, lead microleakage and clinical failure when these monomers were applied in root canal sealers are unavoidable. In order to decrease the polymerization shrinkage of methacrylate monomers, Bowen [2] had synthesized Bis-GMA with a 
molecular weight of 512 using bisphenol A and glycidyl methacrylate (GMA) as raw materials. This new high molecular volume dimethacrylate monomer is the main organic component of the Epiphany $^{\mathrm{TM}}$ root canal sealant, which has recently been applied in the clinic. Unfortunately, microleakage due to polymerization shrinkage of Epiphany ${ }^{\mathrm{TM}}$ still happens [3-6]. Based on their investigations of the relationship between polymerization shrinkage and the conversion of double bonds during polymerization of Bis-GMA, Venhoven et al. [7] revealed that polymerization shrinkage of monomers is directly influenced by the concentration and conversion of the double bonds. In order to solve this high polymerization shrinkage problem, urethane derivatives of Bis-GMA [8], dimethacrylate monomers having bulky substituent groups [9] and multifunctional methacrylate monomers [10-13] have been developed. These monomers are designed to decrease polymerization shrinkage by increasing the molecular weight and molecular volume. In this paper, the authors wish to report the synthesis and characterization of a dimethacrylate monomer with a high molecular weight (634) and a large molecular volume.

\section{Results and Discussion}

Monomer 3 had been previously reported as a component of photocurable resins with good light resistance [14] or protective coatings for optical materials and optical disks [15]. We synthesized this material in two steps by the reactions between 9,9'-bis(4-hydroxyphenyl) fluorene (1) and epichlorohydrin and then methacrylic acid. Scheme 1 illustrates this approach.

\section{Scheme 1.}

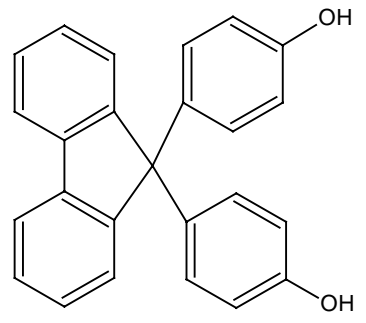

1

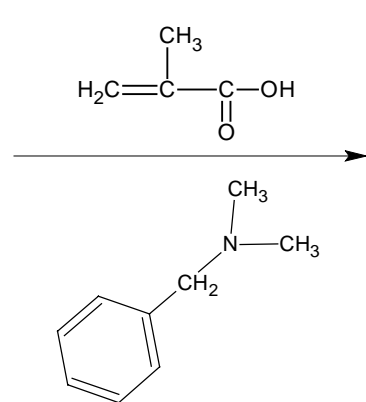

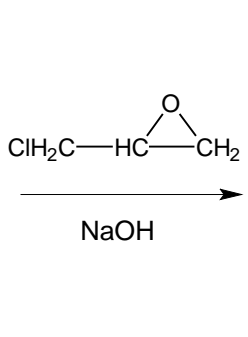

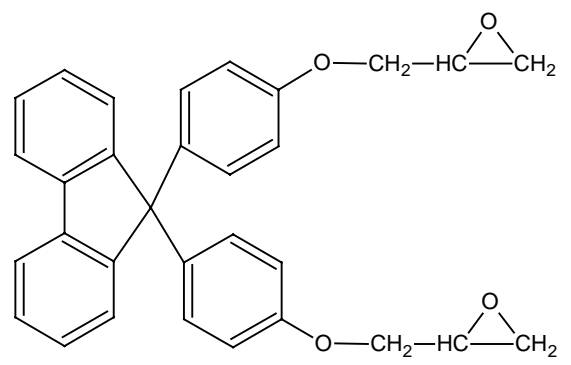

2

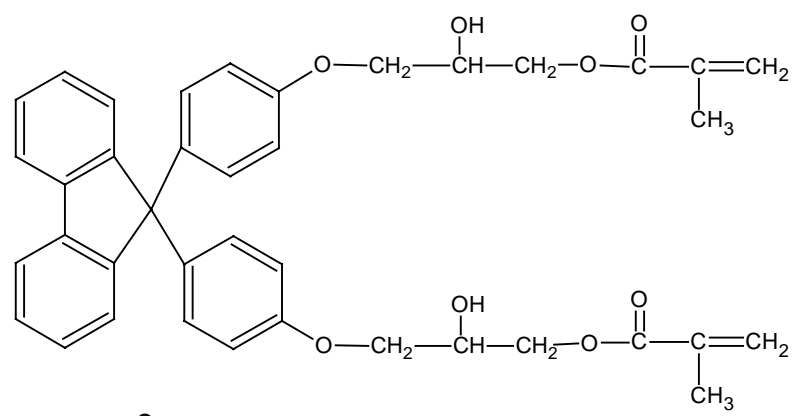

9,9'-Bis(4-oxiranylmethoxyphenyl) fluorene (2) was prepared in $83.0 \%$ yield by the reaction of compound $\mathbf{1}$ and epichlorohydrin. The structure of this intermediate was fully characterized by spectral and elemental analysis data. In its FT-IR spectrum three typical glycidyl ether group absorption peaks were observed at $910 \mathrm{~cm}^{-1}\left({ }_{\mathrm{HC}}^{\stackrel{\mathrm{O}}{-}-\mathrm{CH}_{2}}\right), 2924 \mathrm{~cm}^{-1}\left(\mathrm{O}-\mathrm{CH}_{2}\right)$ and $3002 \mathrm{~cm}^{-1}$ (epoxide $\mathrm{CH}$ and $\mathrm{CH}_{2}$ ) while the absorption peak at $3480 \mathrm{~cm}^{-1}(-\mathrm{OH})$ of starting compound 1 disappeared. This indicated that the 
hydroxyl groups in compound $\mathbf{1}$ had reacted completely with epichlorohydrin and glycidyl ether groups had been introduced into compound 1. The ${ }^{1} \mathrm{H}-\mathrm{NMR}$ spectrum of compound $\mathbf{2}$ could be unambiguously assigned considering the features of ${ }^{1} \mathrm{H}-\mathrm{NMR}$ spectra and the signal intensities. In the mass spectrum of compound 2 , a peak with $\mathrm{m} / \mathrm{z}=462$ also supported the proposed structure.

The target monomer 3 was synthesized in $62.0 \%$ yield by the ring-opening addition reaction of methacrylic acid with compound 2. This reaction was performed using a large excess of methacrylic acid so the excess methacrylic acid may further react with the - $\mathrm{OH}$ group in monomer $\mathbf{3}$ to form the esterification product. Esterification reactions are usually catalyzed by acids such as $\mathrm{H}_{2} \mathrm{SO}_{4}, \mathrm{HCl}$, and $\mathrm{HCOOH}$, and this reaction goes on very slowly in the absence of catalysts [16]. We chose to use a base, N,N-dimethylbenzylamine, as catalyst. Monomer $\mathbf{3}$ was the main product in our reaction and its structure was well characterized.

Compared with FT-IR spectrum of compound 2, mentioned above, the absorption peak at $910 \mathrm{~cm}^{-1}$ disappeared and a new absorption peak at $3413 \mathrm{~cm}^{-1}(-\mathrm{OH})$ appeared in the FT-IR spectrum of compound 3. In ${ }^{1} \mathrm{H}-\mathrm{NMR}$ spectrum of monomer 3 , distinctive signals assigned to $-\mathrm{C}=\mathrm{C}-\underline{\mathrm{H}}$ (6.112

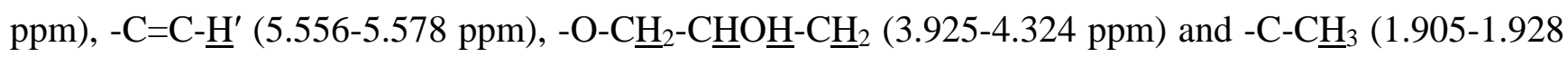
ppm) were observed, while two signals between 3.301-3.338 ppm and 2.728-2.895 ppm corresponding to the epoxide $\mathrm{CH}$ and $\mathrm{CH}_{2}$ groups of the starting material 2 disappeared. This suggests that the epoxy groups in compound 2 reacted completely with methacrylic acid and methacrylate groups were this introduced successfully. In mass spectra of monomer 3 , we could observe the $\mathrm{m} / \mathrm{z}=634$ peak corresponding to the $\mathrm{M}^{+}$ion.

\section{Conclusions}

A dimethacrylate monomer 9,9'-bis[4-(2'-hydroxy-3'-methacryloyloxypropoxy)phenyl] fluorene (3) with a molecular weight of 634 and a large molecular volume was synthesized in 51.4\% total yield in two steps utilizing 9,9'-bis(4-hydroxyphenyl) fluorene (1), epichlorohydrin and methacrylic acid as raw materials. The structures of the intermediate 9,9'-bis(4-oxiranylmethoxyphenyl)fluorene (2) and target monomer 3 were fully characterized by FT-IR, ${ }^{1} \mathrm{H}-\mathrm{NMR}$, mass spectra and elemental analysis.

\section{Experimental}

\section{General}

Chemicals (analytical reagent, unless otherwise stated) were used without further purification. 9,9'Bis(4-hydroxyphenyl) fluorene (1, 97\%), was purchased from Aldrich Chemical Co. (China); epichlorohydrin and anhydrous magnesium sulfate were obtained from Shanghai No. 1 Chemical Reagent Co. Ltd. (China); methacrylic acid (chemical reagent) was purchased from Guangzhou Chemical Reagent Co. Ltd. (China); N,N-dimethylbenzylamine (chemical reagent) was purchased from Shanghai No. 3 Chemical Reagent Co. Ltd. (China); sodium hydroxide, dichloromethane and anhydrous ethanol were purchased from Tianjin Chemical Reagent Co. Ltd. (China); hydrochloric acid was purchased from Guangzhou Donghong Chemical Co. Ltd. (China). FT-IR spectra were measured on a Vector33 Model Fourier Transform Infrared Instrument (Bruker Co. Germany). The samples, in 
the form of $\mathrm{KBr}$ pellets, were scanned from 4000 to $400 \mathrm{~cm}^{-1} .{ }^{1} \mathrm{H}$-NMR spectra were recorded on an Avance AV 400MHz Instrument (Bruker Co., Switzerland); chemical shifts are reported in ppm on the $\delta$ scale with tetramethylsilane as the internal reference and $\mathrm{CDCl}_{3}$ as the solvent. Mass spectra were taken on DSQ Low Resolution Mass Spectrometer (Thermo Co. USA). Elemental analysis was done on a Vario EL CHNS Elemental Analyzer (Element AR Co. Germany). Spectral and elemental analysis data are given in Table 1.

Table 1. Spectral and elemental analysis data for 1-3.

\begin{tabular}{|c|c|c|c|c|}
\hline Compound & $\begin{array}{c}{ }^{\mathbf{1}} \mathbf{H}-\mathbf{N M R} \\
\delta \mathrm{ppm}\end{array}$ & $\begin{array}{c}\text { FT-IR } \\
(\mathrm{KBr}) \mathrm{cm}^{-1}\end{array}$ & $\begin{array}{c}\text { MS } \\
\mathrm{m} / \mathrm{z}(\%)\end{array}$ & $\begin{array}{c}\text { Elemental } \\
\text { analysis } \\
\text { Formula } \\
\text { Calculated \% } \\
\text { Found \% } \\
\end{array}$ \\
\hline 1 & - & $3480(\mathrm{OH})$ & $\begin{array}{l}350 \text { (100), } \\
333 \text { (9.43), } \\
257 \text { (39.17) }\end{array}$ & - \\
\hline 2 & 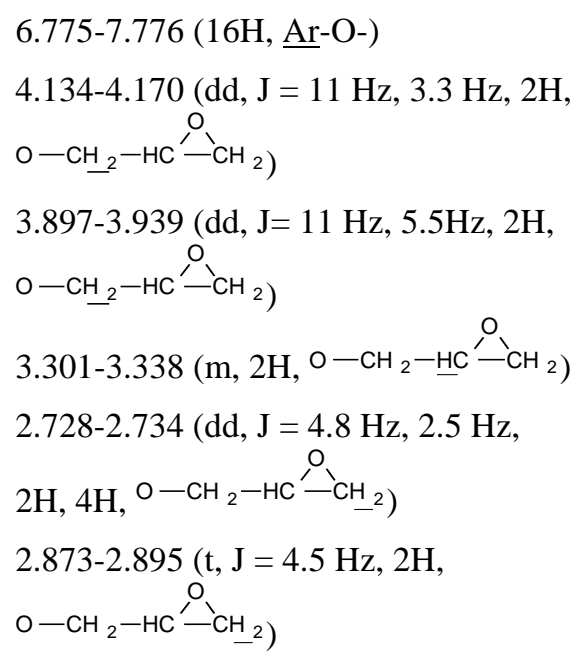 & 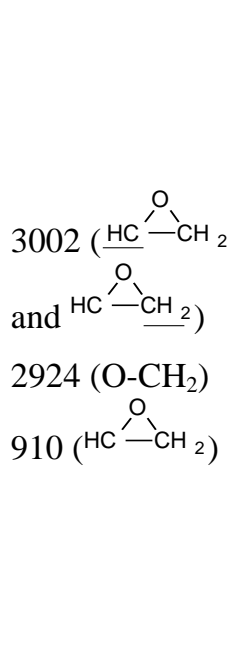 & $\begin{array}{l}462 \text { (100), } \\
405 \text { (17.82), } \\
348 \text { (3.59), } \\
257 \text { (16.73) }\end{array}$ & $\begin{array}{c}\mathrm{C}_{31} \mathrm{H}_{26} \mathrm{O}_{4} \\
\text { C: } 80.52 \mathrm{H}: 5.63 \\
\text { C: } 79.99 \mathrm{H}: 5.66\end{array}$ \\
\hline 3 & $\begin{array}{l}6.708-7.744(16 \mathrm{H}, \underline{\mathrm{Ar}}-\mathrm{O}-) \\
6.112(2 \mathrm{H},-\mathrm{C}=\mathrm{C}-\underline{\mathrm{H}}) \\
5.556-5.578\left(2 \mathrm{H},-\mathrm{C}=\mathrm{C}-\underline{\mathrm{H}}^{\prime}\right) \\
3.925-4.324\left(12 \mathrm{H},-\mathrm{O}-\mathrm{C} \underline{\mathrm{H}}_{2}-\mathrm{C} \underline{\mathrm{HO}} \underline{\mathrm{H}}-\underline{\mathrm{C}}_{2}\right) \\
1.905-1.928\left(6 \mathrm{H},-\mathrm{C}-\mathrm{C} \underline{\mathrm{H}}_{3}\right)\end{array}$ & $\begin{array}{l}3413(\mathrm{OH}) \\
2952\left(\mathrm{CH}_{3}\right) \\
1717(\mathrm{C}=\mathrm{O}) \\
1635(\mathrm{C}=\mathrm{C})\end{array}$ & $\begin{array}{l}634 \text { (7.81), } \\
566 \text { (2.76), } \\
548 \text { (14.18), } \\
492 \text { (5.13), } \\
423 \text { (4.08), } \\
349 \text { (8.25), } \\
257 \text { (31.73), } \\
143(100), \\
69(31.84)\end{array}$ & $\begin{array}{c}\mathrm{C}_{39} \mathrm{H}_{38} \mathrm{O}_{8} \\
\text { C: } 73.82 \mathrm{H}: 5.99 \\
\text { C: } 74.04 \text { H: } 6.01\end{array}$ \\
\hline
\end{tabular}

Preparation of 9,9'-bis(4-oxiranylmethoxyphenyl)fluorene (2)

A mixture of compound 1 (8.00 g, $0.023 \mathrm{~mol}$ ) and epichlorohydrin (20.80 g, $0.223 \mathrm{~mol}$ ) was stirred until a clear solution was obtained. Aqueous $\mathrm{NaOH}$ solution (40 wt \%, $5.50 \mathrm{~g}$ ) was added and the mixture was further stirred for $7 \mathrm{~h}$ at $110 \pm 2{ }^{\circ} \mathrm{C}$. The reaction mixture was filtered, and the filtrate was 
dried under vacuum to remove excess epichlorohydrin, affording a viscous product which was dissolved in small amount of dichloromethane and the resulting solution was added to a mixture of ethyl alcohol/water (3:1, v/v), giving a white precipitate. The precipitate was dissolved in dichloromethane, reprecipitated twice from mixture of ethyl alcohol/water $(3: 1, \mathrm{v} / \mathrm{v})$ and dried to a constant weight under vacuum at $40{ }^{\circ} \mathrm{C}$ to give $8.50 \mathrm{~g}$ (83.0\% yield) of compound 2.

Preparation of 9,9'-bis[4-(2'-hydroxy-3'-methacryloyloxypropoxy)phenyl] fluorene (3)

A mixture of methacrylic acid $(11.50 \mathrm{~g}, 0.134 \mathrm{~mol}), \mathrm{N}, \mathrm{N}$-dimethylbenzylamine (0.1035 g, $\left.7.667 \times 10^{-4} \mathrm{~mol}\right)$ and compound $2(7.00 \mathrm{~g}, 0.020 \mathrm{~mol})$ was stirred at $90 \pm 2{ }^{\circ} \mathrm{C}$ for $10 \mathrm{~h}$. Dichloromethane (50 $\mathrm{mL}$ ) was then added to the reaction mixture. The resulting solution was washed successively with $0.5 \mathrm{M}$ aqueous $\mathrm{HCl}$ and $10 \mathrm{wt} \%$ aqueous $\mathrm{NaOH}$ solution. The organic layer was then dried overnight with anhydrous magnesium sulfate. After removing the drying agent by filtration, the dichloromethane was removed by distillation under vacuum. The product was dried under vacuum at $50{ }^{\circ} \mathrm{C}$ to a constant weight to give $5.59 \mathrm{~g}$ (62.0\% yield) of monomer 3 as a white powder.

\section{References}

1. He, Y. L. Plastic material for dental surgery and its applied formulations. Plast. Sci. Technol. 1999, 23-26.

2. Bowen, R.L. Dental filling material. US Pat. 3066112, 1962.

3. Suprabha, B.S; Sudha, P.; Vidya, M. A comparative evaluation of sealing ability of root canal sealers. Indian J. Dent. Res. 2002, 13, 31-36.

4. Shipper, G.; Orstavik, D.; Teixeira, F.B.; Trope, M. An evaluation of microbial leakage in roots filled with a thermoplastic synthetic polymer-based root canal filling material (Resilon ${ }^{\mathrm{TM}}$ ). $J$. Endod. 2004, 30, 342-347.

5. Heintze, S.D.; Cavalleri, A.; Forjanic, M.; Zellweger, G.; Rousson, V. A comparison of three different methods for the quantification of the in vitro wear of dental materials. Dent. Mater. 2006, 22, 1051-1062.

6. Versiani, M. A.; Carvalho-junior, J. R.; Padilha, M.; Lacey, S.; Pascon, E. A.; Sousa-Neto, M. D. A comparative study of physicochemical properties of $\mathrm{AH}$ Plus ${ }^{\mathrm{TM}}$ and Epiphany ${ }^{\mathrm{TM}}$ root canal sealants. Int. Endod. J. 2006, 39, 464-471.

7. Venhoven, B.A.M.; De Gee, A.J.; Davidson, C.L. Polymerization contraction and conversion of light-curing BisGMA based methacrylate resins. Biomaterials 1993, 14, 871-875.

8. Khatri, C. A.; Stansbury, J. W.; Schultheisz, C. R.; Antonucci J. M. Synthesis, characterization and evaluation of urethane derivatives of Bis-GMA. Dent. Mater. 2003, 19, 584-588.

9. Ge, J.; Trujillo, M.; Stansbury, J. Synthesis and photopolymerization of low shrinkage methacrylate monomers containing bulky substituent groups. Dent. Mater. 2005, 21, 1163-1169.

10. Ahn, K. D.; Chung, C. M.; Kim, Y. H. Synthesis and photopolymerization of multifunctional methacrylates derived from Bis-GMA for dental applications. J. Appl. Polym. Sci. 1999, 71, 20332037. 
11. Chung, C. M.; Kim, J. G.; Kim, M. S.; Kim, K. M; Kim, K. N. Development of a new photocurable composite resin with reduced curing shrinkage. Dent. Mater. 2002, 18, 174-178.

12. Chung, C. M.; Kim, M. S.; Kim, J. G.; Jang, D. O. Synthesis and photopolymerization of trifunctional methacrylates and their application as dental monomers, J. Biomed. Mater. Res. 2002, 62, 622-627.

13. Culbertson, B. M.; Tiba, A.; Sang, J.; Liu, Y. N. Synthesis, characterization and evaluation of new fluorene-based dimethacrylates for formulating dental composites. Polym. Adv. Technol. 1999, 10, 275-281.

14. Okada, S. Curable acrylic resin compositions with good light resistance. Jpn. Kokai Tokkyo Koho JP 2004315744, 2004.

15. Ishii, K.; Yokoshima, M. Resin compositions for optical materials, optical disk materials and cured products thereof. Jpn. Kokai Tokkyo Koho JP 04337307, 1992.

16. Lilja J., Murzin D.Yu., Salmi T.; Aumo, J.; Mäki-Arvela, P.; Sundell, M. Esterification of different acids over heterogeneous and homogeneous catalysts and correlation with the Taft equation. J. Mol. Catal. A: Chem. 2002, 182-183, 555-563.

Sample Availability: Available from the authors.

(C) 2006 by MDPI (http://www.mdpi.org). Reproduction is permitted for noncommercial purposes. 